\title{
Gender Contrasts in Negotiation Impasse Rates
}

\author{
MICHAEL J. COTTER \\ Grand Valley State University, usA \\ cotterm@gvsu.edu \\ JAMES A. HENLEY \\ University of Tennessee at Chattanooga, USA \\ james-henley@utc.edu
}

This study contrasts the rate of impasse in genders in face-to-face negotiations for newly trained women and men. The empirical study analyzed negotiators' negotiation impasse rates based on gender using a two-tailed $t$-test. The bargainers were involved in a series of ten high-stakes, zero-sum game negotiations. A total of 4,855 separate negotiations were examined. Overall, there were no statistically significant differences in the impasse rates of men and women The female rate of impasse was lower than the male rate of impasse, but without any significant differences, the results indicate that there are no gender differences in the abilities of negotiators to arrive at a deal.

Key words: negotiation, gender, impasse

https://doi.org/10.26493/1854-4231.12.3-25

\section{Introduction}

The art and skill of individuals resolving differences to generate an agreement are core elements in bolstering social and business success. Negotiation is a useful and necessary skill in most organizations. For example, the areas of sales and contracts often require negotiation skills to conduct business. In addition to negotiation often being a formal process, it may also be implemented daily by people seeking to secure their desires (Stuhlmacher and Walters 1999).

The potential number of negotiations by people makes knowledge of successful negotiation skills critical. Since the purpose of a negotiation is to come to an agreement so negotiators attain their ultimate goals, a negotiation impasse or deadlock is of considerable consequence. One area of research explores negotiated settlements and negotiated impasses (Mannix, Tinsley, and Bazerman 1995; Olekalns, Smith, and Walsh 1996; O'Connor and Arnold 2001).

Another factor in negotiation research includes the impact of gender on negotiation (Mazei et al. 2015). In combining the areas of gender and impasse, researchers have offered conflicting evidence on 
the impact of gender on negotiation impasses ( $\mathrm{O}^{\prime}$ Connor and Arnold 2001; Riley 2001). Riley (2001) found that women had fewer impasses in negotiations than men, while O'Connor and Arnold (2001) found there were no differences in the rates of negotiation impasses between men and women.

Negotiation parties participate to achieve outcomes that will improve their personal or company's situation. A negotiation impasse does not achieve those outcomes, and the parties fail to achieve their goals. Consequently, a negotiation impasse is a negative outcome to avoid (Tuncel et al. 2016; Bazerman, Tenbrunsel, and Wade-Benzoni 2008). The aversion to the negative outcome of an impasse is so strong, one study found that negotiators would accept a poor negotiated deal to avoid an impasse (Tuncel et al. 2016). Managers need to know causes and factors leading to a negotiated impasse so that an impasse can be avoided. If gender is a factor that could potentially lead to a negotiation impasse, it is important for managers to know this information so they can maximize the probability of a successful negotiated agreement by selecting a negotiator most likely to avoid an impasse. The purpose of this paper is to help clarify gender's influence on negotiation impasses by offering evidence from 4,855 negotiations on the impasse rates of men and women in not achieving a negotiated settlement.

\section{Literature Review of Gender, Outcomes, and Impasses in Negotiation}

The following sections present an overview of the negotiation literature relevant to this study. The literature review includes discussions of gender behavior differences, gender negotiation outcomes, negotiation impasses, and gender and impasses.

\section{GENDER AND BEHAVIOR DIFFERENCES}

Negotiation is not the exclusive domain of one gender as both genders engage in negotiations on a daily basis. Consequently, researchers have examined gender behaviors that could affect negotiation performance (Kimmel et al. 1980; Pruitt et al. 1986; Neu, Grahm, and Gilly 1988; Meyers-Levy 1988; Gerhart and Rhynes 1991; Gayle, Preiss, and Allen 1994; King and Hinson 1994; Min, LaTour, and Jones 1995; Walters, Stuhlmacher, and Meyer 1998; Stuhlmacher and Walters 1999; Eckel and Grossman 2001; Solnick 2001; Kray, Galinsky, and Thompson 2002; O'Shea and Bush 2002; Barron 2003).

To achieve an agreement could require accommodating behaviors by negotiators; accordingly, we examined the negotiation lit- 
erature on this subject as it relates to gender. Eckel and Grossman (2001) found men exhibited more competitive and women more cooperative behaviors. Many other studies have repeatedly categorized women as cooperative and compassionate and men as competitive and aggressive (Fisher and Smith 1969; Tedeschi, Bonoma, and Lindskold 1970; Benton 1975; Kimmel et al. 1980; Pruitt et al. 1986; Scudder 1988; Matheson 1991; Stamato 1992; Watson 1994; Walters, Stuhlmacher, and Meyer 1998; Eckel and Grossman 2001). In a metaanalysis of 62 studies, Walters, Stuhlmacher, and Meyer (1998) found the behaviors of men were more competitive and women more cooperative. However, Walters, Stuhlmacher, and Meyer (1998) also indicated that even though the gender differences were significant, they were also very small and could even vanish or reverse themselves in different negotiations. The cooperative behavior of women may have demonstrated itself in other ways. Some researchers have found women in negotiations are less argumentative and more likely to be influenced by persuasion than men (Eagly and Carli 1981; Major, McFarlin, and Gagnon 1984). Kimmel et al. (1980) found that women were less likely to use pressure tactics in negotiations. Eriksson and Sandberg (2012) found that men were more likely to initiate a negotiation when the adversary was a woman. In terms of initial offers, one study has suggested that women make higher initial offers than men do; however, their findings have not been statistically significant (Eckel and Grossman 2001). Another study found that women made higher initial offers than men do when the negotiating opponent was a male, but the finding was not statistically significant (Solnick 2001). Kulik and Olekalns (2012) suggest that out of the norm behavior for a gender such as agentic behavior for females could create a negotiation backlash and lower outcomes.

There is also evidence of no differences in the negotiation behavior of men and women. Categorizing the female behavior as communal and male behavior as agentic, Meyers-Levy (1988) found no differences in the behaviors of men and women when the sex roles were not incited. Min, LaTour, and Jones (1995) examined the easing of a hard negotiation stance to a softer stance and did not find any differences in the genders. Other researchers also found no competitive difference between men and women (Grant and Sermant 1969; Horai and Tedeschi 1975; Ferguson and Schmitt 1988; Wall and Blum 1991; Watson and Hoffman 1996). There is also evidence of no cooperative differences between men and women. Studying cooperative negotiation techniques, Mintu-Wimsatt and Gassenheimer (2002) found no gender differences. 
Finally, there is evidence that runs counter to the cooperative female and competitive male. Some researchers found that women are more competitive and less cooperative negotiators than men (Oskamp and Pearlman 1965; Bedell and Sistrunk 1973; Hottes and Kahn 1974).

\section{GENDER NEGOTIATION OUTCOMES}

The goal of any negotiator whether male or female is the outcome of the negotiation such as units sold, price, etc. Since researchers have found mixed results in differences in negotiation behavior between the genders, it is not surprising that the negotiated-outcomes successes between the genders also have mixed results.

Numerous studies researching the impact of gender on negotiation outcomes found that men had better results than women did. In a meta-analysis, Mazei et al. (2015) found in negotiations that men reached better economic results than women, but the results for men were lessened when the negotiator had experience, the negotiator had information about the bargaining parameters, and the negotiator was bargaining for another person. Herbst, Dotan, and Stōhr (2017) discovered male negotiation teams that were not friends performed better than female negotiation teams that were not friends. Kray, Kennedy, and Van Zant (2014) researched deception in negotiations and found that women were deceived more than men. In an automobile negotiation study, men negotiated better automobile prices than women (Tubbs, Ottenbreit, and Falk 2008). Although participants in Solnick's (2001) study were unaware of their opponent's gender, Solnick found men generated higher earnings than women. Similarly, King and Hinson (1994) found that men had greater success in negotiations than women. In a meta-analysis of 21 studies, Stuhlmacher and Walters (1999) concluded that men had more successful outcomes than women did. Riley (2001) found that in ambiguous negotiation situations, men negotiated larger agreement payoffs.

Other studies failed to find any negotiation outcome differences between the genders. Xiu, Kang, and Roline (2015) discovered that in salary negotiations women asked for no less salary than their male counterparts. In situations where outcomes benefited both negotiators, Kimmel et al. (1980) found no outcome differences between men and women. Stevens, Bavette, and Gist (1993) did not discover any differences in behavior or profits between the genders when the negotiators were trained in self-management and negotiation techniques. After the initial negotiation, Min, LaTour, and Jones (1995) unearthed few differences in gender negotiation outcomes. A study 
by Pruitt et al. (1986) determined that men and women had no differences in contentious behavior or outcome success with a constituent attending.

\section{NEGOTIATION IMPASSE LITERATURE}

For many negotiators, a negotiation impasse is a negative outcome to be avoided. For example, Bazerman, Tenbrunsel, and Wade-Benzoni (2008) found that even sacrosanct issues became negotiable when an impasse was unacceptable.

Since an impasse is a negative outcome, much of the literature on impasses has been on identifying factors that lead to an impasse. While studying the use of true statements to misled people (paltering), Rogers et al. (2017) discovered the use of paltering in negotiations increases the probability of an impasse. Cohen, Leonardelli, and Thompson (2014) discovered that two- and three-person negotiation teams were more likely to reach an impasse than single negotiators. Wiltermuth and Neale (2011) found that negotiators that had information irrelevant for the negotiation about their negotiation counterpart were more likely to reach an impasse. Uncertainty in revenues and costs can result in a negotiation impasse (Moon, Yao, and Park 2011). For a negotiator, failing to reach an agreement in previous negotiations is likely to lead to an impasse in the negotiator's subsequent negotiations ( $\mathrm{O}^{\prime} \mathrm{C}$ onnor, Arnold and Burris 2005). Misleading offers early in a negotiation by one party increases the likelihood of an impasse (Bac 2001). Researchers found that when the supervisors' expectations were greater than the subordinate negotiators' abilities, negotiations were more likely to end in an impasse (Wolfe and Murthy 2005-2006). The use of a third party such as an agent for the negotiation is more likely to lead to an impasse (Bazerman et al. 1992). Novice negotiators believe that negotiation impasses occur frequently (O'Connor and Adams 1999). In the presence of a crises, a negative social climate will lead to less movement toward a negotiated deal and to more movement toward an agreement when the social climate is positive (Druckman, Olekalns, and Smith 2009).

Other researchers have uncovered factors that lead to agreements. Trotschel et al. (2011) found that taking into account the perspective of a negotiator's opponent helped to avoid an impasse. Alexander, Schul, and McCorkle (1994) found that negotiators using more coordinating behavior were less likely to end in an impasse. Jap, Anderson, and Hamilton (2011) found that negotiators that had a rapport were less likely to reach an impasse and more likely to reach 
an agreement. Similarly, the existence of a social relationship between the negotiators is likely to lead to more agreements and less impasses (Moore et al. 1999; Pesendorfer and Koeszegi 2007). When a negotiator views the initial offer as a gain and not a loss, the negotiation is more likely to reach agreement and less likely to lead to an impasse (Kristensen and Garling 1997). Chandler and Judge (1998) found the chief negotiator who was higher in the organization was less likely to reach an impasse.

In negotiation literature, there are discussions of both distributive and integrative negotiation styles (Olekalns, Smith, and Walsh 1996). The distributive approach is more competitive, while the integrative is more cooperative. Each orientation has two types of likely negotiation outcomes. Olekalns, Smith, and Walsh (1996) stated the distributive orientation outcomes are impasse and win-lose, while the integrative outcomes are suboptimum and optimum. The authors further claimed the suboptimum and optimum integrative outcomes yield higher profits for both negotiators while the distributive outcome of win-lose yields lower profits and an impasse would yield no profit. The profit advantage might indicate an integrative orientation would be preferred over the distributive orientation. Further, the integrative orientation is considered the quality orientation (Olekalns, Smith, and Walsh 1996). However, both orientations are employed.

Mannix, Tinsley, and Bazerman (1995) studied repeated negotiations occurring over time. They found greater negotiator mobility resulted in fewer integrative agreements. Mobility refers to a negotiator's capacity to move on to deal with other negotiators over time and with a lower probability of encountering the same negotiator again. Hence, the negotiator is not likely to make a concession in the current negotiation because there may not be opportunities for reciprocity from the other negotiator in future negotiations. Consequently, high mobility tends to result in a distributive orientation.

O'Connor and Arnold (2001) conducted a series of three studies examining negotiation impasses and self-efficacy. Specifically, they examined the impact of a prior negotiation impasse on the subsequent negotiation experience. They found negotiators who experience an impasse are likely to enter a distributive spiral. In this spiral, the negotiator views the impasse as an unsuccessful outcome and perceives the negotiator's counterpart as unwilling to reach an agreement. Then the negotiator is not likely to work with the counterpart in the future and develops a negative attitude toward negotiation as a solution means. The researchers found this downward spiral made it more difficult to reach future negotiated deals. However, 
results offered limited evidence that negotiators with high levels of self-efficacy tended to avoid this downward spiral.

\section{IMPASSE AND GENDER}

With so much evidence pointing to the cooperative female and competitive male (Walters, Stuhlmacher, and Meyer 1998), a logical assumption in terms of negotiation would be that women would tend to use a more of an integrative style of negotiation and therefore have fewer impasses, and men would use a more distributive style and have more impasses. However, there is contradictory evidence of gender differences in reaching an impasse. Riley (2001) studied 689 negotiations in a MBA negotiation class. As the literature would predict for the competitive male and cooperative female, Riley (2001) found that males were more likely to have an impasse, and females were more likely to avoid an impasse. In contrast, there is evidence of no gender differences in reaching an impasse. As by-product of their studies on impasses and self-efficacy, O'Connor and Arnold (2001) found no differences in impasse rates of males and females. In three studies, they used undergraduate students in an introductory management course negotiating with each other for course credit. For each of their studies, they used the following samples: study one included 58 negotiations, study two included 83 negotiations, and study three included 91 negotiations. In all three studies, O'Connor and Arnold (2001) reported no differences in the levels of impasse based on gender.

\section{NEGOTIATION IMPASSE HYPOTHESES}

From the literature review, there is a conflict in results whether or not there are any differences in likelihood of one gender or the other more likely to reach a negotiation impasse. One study concluded that males were more likely to have an impasse and females less likely Riley (2001). Another study concluded there were no differences in impasse rates between male and female negotiators O'Connor and Arnold (2001), and there were no studies reporting females with a higher impasse rate that males. Consequently, we approached our study from a neutral position and did not anticipate one gender to have fewer impasses than the other gender. Accordingly, the study used null hypotheses. The purpose of the study was to find further evidence supporting either Riley's (2001), O'Connor and Arnold's (2001), or neither studies' conclusions.

To analyze thoroughly gender influence on negotiation impasses, the paper considered eight null hypotheses. The study analyzed the 
overall impasse results of men and women, and the impasse rates of men and women in both the buyer and seller roles. The eight null hypotheses are below.

$\mathrm{H} 1$ There is no difference in the impasse rate of negotiations when contrasting women and men for all negotiations.

$\mathrm{H} 2$ There is no difference in the impasse rate of negotiations when contrasting women and men acting as the buyer.

$\mathrm{H} 3$ There is no difference in the impasse rate of negotiations when contrasting women and men acting as the seller.

$\mathrm{H} 4$ There is no difference in the impasse rate of negotiations when male seller versus male buyer dyads are compared to male seller versus female buyer dyads.

$\mathrm{H} 5$ There is no difference in the impasse rate of negotiations when male seller versus male buyer dyads are compared to female seller versus male buyer dyads.

н6 There is no difference in the impasse rate of negotiations when male seller versus male buyer dyads are compared to female seller versus female buyer dyads.

$\mathrm{H} 7$ There is no difference in the impasse rate of negotiations when female seller versus male buyer dyads are compared to female seller versus female buyer dyads.

H8 There is no difference in the impasse rate of negotiations when of male seller versus female buyer dyads are compared to female seller versus female buyer dyads.

\section{Negotiation Methods and Data}

Our study used student negotiators in a negotiation class. It is common for negotiation studies to use student negotiators for experimental research (Stuhlmacher and Walters 1999). In doing so, it brings into question the level of students' motivation to succeed in the negotiation, especially as compared to the potentially intense need to succeed of 'real world' negotiators.

In our study, the students had a significant motivation to reach an agreement and be more successful than their opponents. The students were part of a negotiation class in which the students were trained in negotiation strategies and tactics for the first half of the semester and negotiations took place in the second half of the semester. Fifty percent of each student's course grade was determined by the outcome of a series of negotiations in the second half of the semester. Consequently, completing the negotiation and beating their opponents was paramount. Although, the stakes in our 
study are different from negotiators' stakes in actual business situations, the pressure the students appeared to feel to succeed was rather intense.

The negotiations took place in a negotiation course at a state institution with a student population of about 24,000 . The course was an upper-class course consisting of sophomores, juniors, seniors, and graduate students. The vast majority were juniors and seniors.

The procedure for the series of negotiations required the students to engage in ten different one-on-one, face-to-face negotiations with other students over ten class days in the classroom during the class session. The students were randomly paired together for the negotiations. The students did not know who their counterpart was until just before negotiation began. Because the negotiation match-ups were random for each session, it often happened that the students face the same partner more than once in the ten negotiations. The possibility of having to face the same opponent at a later time (with the exception of the tenth negotiation) may impact how negotiations were conducted by students.

\section{PRIOR TO NEGOTIATION SESSIONS}

In a class session well before the first day of negotiation, the professor explained the negotiation scenario that served for all negotiations. In short, both buyer and seller worked for different firms with the capacity to manufacture an unnamed product. The professor guaranteed the total costs of manufacturing were lower for the seller than the buyer (although not necessarily for each variable taken alone). The buyer sought to purchase the manufactured product from the seller below the buyer's costs. The seller sought to make a sale to the buyer above the seller's costs. The difference between the seller's and buyer's manufacturing costs constituted the deal's profit potential. The percentage of profit ranged between $o$ and 100 percent. The percentage of the profit secured by each party in the deal gave them their negotiation score for the day. So, if the deal showed the seller got 60 percent of the profit, it showed the buyer earned 40 percent of the profit. It was a zero-sum game.

The negotiation information specified the exact quantity of the product involved in the deal so both seller and buyer knew that detail. Negotiation did not change the deal quantity.

Also prior to the first negotiation session, the professor flipped a coin in class and then declared whether the buyer or seller in the match-ups made the first offer on the first variable considered in the negotiation for the entire semester. After the first variable was 
considered, then the negotiators made their own determination as to who initiated offers on variables. To reduce confusion, this determination lasted for all ten negotiations in the semester.

Time was allocated during class about a week before negotiations commenced to hand out copies of contracts to be used in the initial negotiations. During the same day, the professor demonstrated how the contract was filled out and how calculations were made to complete the number portion of the contract. The professor also pointed out the area for signatures and other information that must be completed on the contract.

The professor explained that while he would wander the room and observed the 20 or so negotiations taking place simultaneously, the professor offered no input into the dealing. Explanations of the contracts and how calculations were performed to arrive at an accurate total deal financial figure had already occurred in classes well before the week when negotiations began. It was made clear that each student was now handling the dealing independently and would have to live with the consequences of any errors on the contract.

The professor also explained that each student's cost information in all ten negotiations were unique. Every student in every negotiation would have unique information about variable costs that can vary enormously from one negotiation to the next. A negotiation seller may have product variable costs in the pennies while sitting right next to them another negotiation seller would have product variable costs in the thousands of dollars. In short, the negotiators could not count on the numbers from the past to guide them. They had to count on their ability to 'read' the other party and execute the dealing techniques, both of which were covered in class lectures in the first half of the semester.

The professor pointed out that in calculating the profit in the contract, the professor used either the individual variable agreements and made a summary calculation or the total deal agreement found on the completed contract. This encouraged students to not sidestep negotiating each of the variables. An objective of the class was to get repeated practice in the art of negotiation with something at stake, not to find a way of reducing practice. The professor specified exactly what time the student had to be in the classroom to participate in the negotiation for all days. Typically, the professor gave a minilecture for the first 15 minutes of the class and the student had to be in the room at least 15 minutes after the class time begins. Since some students relied on campus bus service which can be irregular during harsh weather, this offered students a small buffer. 
The procedure for the series of negotiations required the students to engage in ten different one-on-one and face-to-face negotiations with other students over ten class days. The students were randomly paired together for the negotiations.

During each negotiation, the students dealt with five to ten variables specified by the professor. These specific variables were common dimensions such as shipping costs, pallet costs, etc. that could be part of a manufacturing agreement. One by one, each student was handed a confidential printed sheet that showed costs of each of the variables for the firm represented by the negotiator, the product quantity in the deal, and told the student whether she or he was a buyer or seller in the negotiation. Each student then transferred that cost information onto a separate sheet of paper. The professor then picked up the original information sheet from each student. So, at this time, the student understood the negotiation figures, the role as buyer or seller, but did not know who the opponent would be.

The professor then revealed the random match-ups between buyers and sellers on a large screen. Each student called out the number of their opponent, they found each other, found a place to sit, introduced themselves, and began the negotiation. A preprinted contract that indicates the variables and quantities with a place for a total deal financial figure and area for printed names and signatures was handed out by the professor within minutes of opponents finding each other. When the contract had been completed and signed by both parties, the contract was lifted overhead and picked up by the professor.

The time chosen for each negotiation was around five minutes per variable to negotiate. Each negotiation session lasted between 25 to 40 minutes depending on the number of variables needed to resolve. All negotiations on a given day had the same number of variables. Time remaining was measured by an inexpensive, windup kitchen timer with an alarm sound. While a precise timer device could be used, the use of the kitchen timer with a fairly wide latitude in accuracy was preferred to provide students even more uncertainty in the dealings.

During the negotiations, the professor would consult the timer and then write the approximate number of minutes left to negotiate on the whiteboard. Since the timer was reliably unreliable, at the 3minute mark the professor erased time information from the board to let the students know the alarm could go off at any moment. The

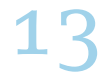


professor then moved to a position to permit optimal observation of those students still negotiating.

\section{THE CONTRACT}

The preprinted contract showed each of the variables encompassed in the deal. Each variable must be negotiated and the agreed price had to be written on the contract. The final financial deal total which had to be calculated based on the prices of each variable and the quantity involved had to be written on the contract. Each negotiator had to sign the contract next to their printed name. All these tasks had to be performed to have the contract considered complete. Further, the completed contract had to be raised above the head by the person who made the first offer of the negotiation before the alarm rings to indicate negotiation time ended. The professor was in a position such that he can see the entire room at the time the alarm rings to clearly sort out who performed as instructed. It was made extremely clear to all students that negotiators beat the deadline or they did not. A lack of credibility on this issue could easily lead to considerable problems. The contract was completely filled out or it was not. The completed contract was raised above the head or it was not. There was no uncertainty. In short, no one has an unfair advantage in a situation of known absolutes.

If students did not negotiate each variable and write in the agreed price on the contract, calculate and write in the total deal price, sign the contract, and hold it overhead before the alarm rings, both students received a ' $o$ ' for the day.

\section{STUDENT MOTIVATION}

In the role of buyer or seller, the goal for each of the students was to generate a greater percentage of the possible profit. The percentage could range from o to 100 percent and was used to tabulate the student's negotiation grade. If a student failed to show for a negotiation, the absent student received a ' $\mathrm{o}$ ' and the opponent received a '100.' These scores were not included in the analysis. The professor established the prices that would assure a profit in the negotiation. Each negotiation had unique prices for each of the variables for each student for all ten negotiation sessions.

Because the negotiations were 50 percent of the student's grade, the students were very aware of the need to succeed in negotiations and best their opponents. Naturally, this circumstance resulted in very competitive student behavior. Although controlling one's temper was strongly stressed during the lecture portion of the course, it 
was not uncommon to have students lose their composure. Despite occasional emotional outbursts, the vast majority of the student negotiators overcame their emotions to complete a deal.

From 1999 to 2013, 4855 student zero-sum negotiations were monitored. The focus of this study was gender contrasts in not reaching a deal. If an impasse occurred and the negotiators did not reach an agreement by the end of the allotted time, both the seller and buyer students received a ' $\mathrm{o}$ ' for the negotiation. Consequently, there was intense pressure to reach an agreement. Students failed to reach an agreement in 155 negotiations and reached an agreement in 4700 negotiations.

\section{Negotiation Results}

To investigate the impact of gender on negotiation impasses, the paper studied eight hypotheses stated in the null form. The hypotheses were tested using a two-tailed $t$-test. To determine any significant differences in the data, the standard was a $p$-value of .05. The eight hypotheses, test results, and hypotheses test results table are below.

\section{OVERALL IMPASSE HYPOTHESIS AND RESULTS \\ FOR MEN AND WOMEN}

In Hypothesis 1, the negotiator's ability to arrive at a deal is studied by comparing the results of men and women. The results are an overall evaluation of the impasse rates regardless of whether the negotiator was in a buyer or seller role or of the gender of the opponent.

$\mathrm{H} 1$ There is no difference in the impasse rate of negotiations when contrasting women and men for all negotiations.

The mean impasse rate for women was $2.84 \%$ of a possible $100 \%$. This indicates that women arrived at a deal during $97.16 \%$ of negotiations begun. Men's mean impasse rate was 3.43\%. A two-tailed $t$-test analysis contrasting the genders' negotiation impasse rates showed $t$ $=1.651$ with a resulting $p$-value of .099 with 8729 degrees of freedom. Null hypothesis $\mathrm{H} 1$ is not rejected.

\section{IMPASSE HYPOTHESES AND RESULTS FOR WOMEN AND MEN IN BUYING AND SELLING ROLES}

It is possible the buyer or seller roles of the negotiator could also have an impact on the impasse rate. In Hypotheses 2 and 3, gender comparisons were made of negotiation outcomes when taking on the roles of buyers and sellers. 
$\mathrm{H} 2$ There is no difference in the impasse rate of negotiations when contrasting women and men acting as the buyer.

The mean impasse rate for women acting as the buyer was $2.76 \%$ while the men's mean impasse rate as a buyer was 3.48\%. A twotailed $t$-test analysis contrasting the genders' negotiation impasse rates showed a $t=1.429$ with a resulting $p$-value of .153 with 4417 degrees of freedom. Null hypothesis $\mathrm{H} 2$ is not rejected.

н3 There is no difference in the impasse rate of negotiations when contrasting women and men acting as the seller.

The mean impasse rate for women acting as the seller was $2.91 \%$. Men's mean impasse rate as a seller was $3.38 \%$. A two-tailed $t$-test analysis contrasting the genders' negotiation impasse rates showed a $t=.895$ with a resulting $p$-value of .371 with 4853 degrees of freedom. Null hypothesis $\mathrm{H} 3$ is not rejected.

\section{NEGOTIATING DYADS' IMPASSE HYPOTHESES AND RESULTS}

Hypotheses 4 through 8 considered the opponent's gender and role (buyer or seller) by comparing the impasse rates between negotiating dyads. The negotiators' genders and roles varied in the dyads and hypotheses.

$\mathrm{H} 4$ There is no difference in the impasse rate of negotiations when male seller versus male buyer dyads are compared to male seller versus female buyer dyads.

The mean impasse rate when male sellers competed with male buyers was $3.88 \%$. When male sellers competed with female buyers, the mean impasse rate was $2.65 \%$. A two-tailed $t$-test analysis contrasting the pairings negotiation impasse rates showed a $t=1.869$ with a resulting $p$-value of .062 with 2842 degrees of freedom. Null hypothesis $\mathrm{H} 4$ is not rejected.

$\mathrm{H} 5$ There is no difference in the impasse rate of negotiations when male seller versus male buyer dyads are compared to female seller versus male buyer dyads.

The mean impasse rate when male sellers competed with male buyers was $3.88 \%$. When female sellers competed with male buyers, the mean impasse rate was $2.90 \%$. A two-tailed $t$-test analysis contrasting the pairings negotiation impasse rates showed a $t=1.457$ with a resulting $p$-value of .145 with 2794 degrees of freedom. Null hypothesis $\mathrm{H} 5$ is not rejected.

н6 There is no difference in the impasse rate of negotiations when male seller versus male buyer dyads are compared to female seller versus female buyer dyads. 
TABLE 1 Hypotheses Test Results Table

\begin{tabular}{lrrr}
\hline Hypoth. & Impasse Negotiation Rates (\%) & Impasse Negotiation Rates (\%) & $p$ \\
\hline H1 & Females 2.84 & Males 3.43 & 0.099 \\
H2 & Female Buyers 2.76 & Males Buyers 3.48 & 0.153 \\
H3 & Female Sellers 2.91 & Male Sellers 3.38 & 0.371 \\
H4 & MS vs. MB 3.88 & MS vs. FB 2.65 & 0.062 \\
H5 & MS vs. MB 3.88 & FS vs. MB 2.90 & 0.145 \\
H6 & MS vs. MB 3.88 & FS vs. FB 2.93 & 0.227 \\
H7 & FS vs. MB 2.90 & FS vs. FB 2.93 & 0.969 \\
H8 & MS vs. FB 2.65 & FS vs. FB 2.93 & 0.721 \\
\hline
\end{tabular}

NoтеS FB - Female Buyer, мв - Male Buyer, Fs - Female Seller, ms - Male Seller.

The mean impasse rate when male sellers competed with male buyers was $3.88 \%$. When female sellers competed with female buyers, the mean impasse rate was $2.93 \%$. A two-tailed $t$-test analysis contrasting the pairings negotiation impasse rates showed a $t=1.208$ with a resulting $p$-value of .227 with 1516 degrees of freedom. Null hypothesis $\mathrm{H} 6$ is not rejected.

$\mathrm{H} 7$ There is no difference in the impasse rate of negotiations when female seller versus male buyer dyads are compared to female seller versus female buyer dyads.

The mean impasse rate when female sellers competed with male buyers was $2.90 \%$. When female sellers competed with female buyers, the mean impasse rate was $2.93 \%$. A two-tailed $t$-test analysis contrasting the pairings negotiation impasse rates showed a $t=.039$ with a resulting $p$-value of .969 with 1920 degrees of freedom. Null hypothesis $\mathrm{H} 7$ is not rejected.

$\mathrm{H} 8$ There is no difference in the impasse rate of negotiations when of male seller versus female buyer dyads are compared to female seller versus female buyer dyads.

The mean impasse rate when male sellers competed with female buyers was $2.65 \%$. When female sellers competed with female buyers, the mean impasse rate was $2.93 \%$. A two-tailed $t$-test analysis contrasting the pairings negotiation impasse rates showed a $t=.357$ with a resulting $p$-value of .721 with 1443 degrees of freedom. Null hypothesis $\mathrm{H} 8$ is not rejected.

\section{Summary and Discussion}

The overall objective of this paper is to compare the impact of gender on the rate of impasse outcomes in a zero-sum game situation. To accomplish this objective, 4,855 negotiations were analyzed. Eight 
hypotheses were evaluated to determine if any gender differences occurred in the likelihood of negotiations ending in an impasse. Although, women had lower rates of impasse, none of the hypotheses showed any statistically significant differences. Consequently, our study showed no significant differences in the genders in arriving at a negotiation impasse.

Hypothesis 1 examined the negotiation impasse rate of women compared to men over all negotiations. The male rate of impasse was higher than the female impasse rate but was not statistically significant at the .05 level. This finding supports the O'Connor and Arnold (2001) finding of no statistically significant difference between males and females in reaching or avoiding an impasse, and contrasts with the Riley (2001) conclusion that females were less likely to arrive at an impasse and males more likely to reach an impasse.

Next, we considered the gender of the negotiator in combination with the buyer and seller roles. In the buyer role, Hypothesis 2 testing showed that female buyers had lower impasse rates than male buyers, but the difference was not statistically significant. Hypothesis 3 revealed the impasse rate of female sellers was slightly lower than the impasse rate of male sellers, but the difference between the rates was not statistically significant.

Finally, the impasse rates of negotiating dyads were compared to one another in Hypotheses 4 through 8. Each dyad consisted of a seller and buyer. We also isolated the genders in the seller and buyer roles. None of the hypotheses revealed any significant difference in impasse rates between the dyads.

Although we did not find any statistically significant differences, we did find that overall women negotiators had lower impasse rates than male negotiators, women buyers had lower impasse rates than men buyers, and women sellers did have lower impasse rates than men sellers. Considering this information, it is a little more understandable as to why previous research had conflicting results with Riley (2001) finding females to have lower impasse rates than males at a significant level and O'Connor and Arnold (2001) finding no significant differences in male and female impasse rates.

As stated earlier, this study supports the O'Connor and Arnold (2001) conclusion that there were no statistically significant differences between the impasse rates of male and female negotiators. O'Connor and Arnold (2001) used three studies to arrive at their conclusion. The first study used 58 negotiations, the second study used 83 negotiations, and the third study used 91 negotiations. Our contribution beyond O'Connor and Arnold (2001) study lies the depth 
of our sample and longitudinal nature of the study. Our study analyzed 4,855 negotiations of which 155 resulted in an impasse. The negotiations were collected from a 14-year period from 1999 to 2013.

\section{Management Implications}

The results offer some interesting and possibly useful information for managers. Overall, females achieved a lower impasse rate than males. However, the difference between females and males was not statistically significant. If avoiding a negotiated impasse is critical, our study did not show any significant differences in the genders. Consequently, the gender of the negotiator should not increase the likelihood of an impasse.

A major management implication not addressed in this analysis is the outcomes of the negotiations. While this paper examines the impasse rate in arriving at a negotiation deal, it does not consider the impact of the deals that are stuck. In short, arriving at a completed deal in which one party gains zero profit may not be better than not striking the deal. All negotiation situations examined in this study did have a profit built in, although the amount of profit was unknown to the negotiators. In the 'real world,' negotiators may often face circumstances in which no reasonable profit is possible and arriving at an impasse conclusion is optimal.

\section{Study Limitations}

Although common in negotiation studies, the first limitation is the inclusion of students as the negotiators. Although, detail has gone into providing a strong motivation by using grades for students to perform at their maximum ability, the pressure may not be the same as business negotiators facing career implications based on their performances. In addition, some students may not be as concerned about their specific grades, consequently, lowering the motivation of those students.

A second limitation is not allowing the possibility of a win-win situation for the students. Our study used only a zero-sum game. In actual business negotiations, business negotiators often develop long-term relationship with their counterparts in negotiation settings. In those situations, a win-win strategy may be the preferred outcome. Consequently, the negotiation behaviors in a win-win negotiation could be very different from a zero-sum negotiation.

The selection of the student sample for the study is a third limitation for the study. The students were not randomly selected for the negotiations. The negotiation course is an elective for the students. 
Therefore, only the students with an interest in negotiation take the course. Not everyone interested in the course can take the course. The course nearly always reaches the cap for the number of students allowed in the course thereby leaving some students with an interest in negotiation out of the course. These problems could cause the results to differ from the way an average person would behave in a negotiation setting.

Another limitation for the study is the lack of any product information for the students. The students are negotiating over price for an unnamed product. The reason is so that one negotiator could not have a possible product information advantage. However, this is very different from 'real-world' negotiations where negotiators have product and previous price information readily available.

\section{Further Research}

The focus of our study was to determine if there were gender differences in rates of completing a negotiation. O'Connor and Arnold (2001) reported no difference in the impasse rates between the genders, while Riley (2001) reported that women arrived at fewer impasses than men. Our results supported O'Connor and Arnolds' (2001) finding of no differences in gender impasse rates. Although we did not find any statistically significant differences, we did find that overall women negotiators had lower impasse rates than male negotiators. With disagreement on whether or not gender is a factor in impasse outcomes, there is a need for more research in the area.

The methodology of the negotiation process could be altered in future research to further understand the situations where a deal or no deal could occur. No negotiation time limits, allowing 'win-win' negotiations, and team negotiations could all be investigated. Finally, the research could be conducted using professional negotiators in 'real world' settings to see if the findings concur with this study's results.

\section{References}

Alexander, J. F., P. L. Schul, and D. E. McCorkle. 1994. 'An Assessment of Selected Relationships in a Model of the Industrial Marketing Negotiation Process.' The Journal of Personal Selling and Sales Management 14 (3): 25-41.

Bac, M. 2001. 'On Creating and Claiming Value in Negotiations.' Group Decision and Negotiation 10 (3): 237-51.

Barron, L. A. 2003. 'Ask and You Shall Receive? Gender Differences in Negotiators' Beliefs about Requests for a Higher Salary.' Human Relations 56 (6): 635-62. 
Bazerman, M. H., M. A. Neale, K. L. Valley, E. J. Zajac, and Y. M. Kim. 1992. 'The Effect of Agents and Mediators on Negotiation Outcomes.' Organizational Behavior and Human Decision Processes 53 (1): 55-73.

Bazerman, M. H., A. Tenbrunsel, and K. Wade-Benzoni. 2008. 'When "Sacred" Issues Are at Stake.' Negotiation Journal 24 (1): 113-7.

Bedell, J., and F. Sistrunk. 1973. 'Power, Opportunity Costs, and Sex in a Mixed- Motive Game.' Journal of Personality and Social Psychology 25:219-26.

Benton, A. A. 1975. 'Bargaining Visibility and the Attitudes and Negotiation Behavior of Male and Female Group Representatives.' Journal of Personality 43:661-75.

Chandler, T. D., and T. A. Judge. 1998. 'Management Chief Negotiators, Bargaining Strategies, and the Likelihood of Impasse in Public Sector Collective Bargaining.' American Review of Public Administration 28 (2): 146-65.

Cohen, T. R., G. J. Leonardelli, and L. Thompson. 2014. 'Avoiding the Agreement Trap: Teams Facilitate Impasse in Negotiations with Negative Bargaining Zones.' Negotiation and Conflict Management Research 7 (4): 232-42.

Druckman, D., M. Olekalns, and P. L. Smith. 2009. 'Interpretive Filters: Social Cognition and the Impact of Turning Points in Negotiation.' Negotiation Journal 25 (1): 13-30.

Eagly, A. H., and L. L. Carli. 1981. 'Sex of Researchers and Sex-Typed Communications as Determinants of Sex Differences in Influenceability: A Meta-Analysis of Social Influence Studies.' Psychological Bulletin 90:1-20.

Eckel, C. C., and P. J. Grossman. 2001. 'Chivalry and Solidarity in Ultimatum Games.' Economic Inquiry 39 (2): 171-88.

Eriksson, K. H., and A. Sandberg. 2012. 'Gender Differences in Initiation of Negotiation: Does the Gender of the Negotiation Counterpart Matter?' Negotiation Journal 28 (4): 407-28.

Ferguson, E. D., and S. Schmitt. 1988. 'Gender-Linked Stereotypes and Motivation Affect Performance in the Prisoner's Dilemma Game.' Perceptual and Motor Skills 66:703-14.

Fisher, R., and W. P. Smith. 1969. 'Conflict of Interest and Attraction in the Development of Cooperation.' Psychonomic Science 14:154-5.

Gayle, B. M., R. W. Preiss, and M. Allen. 1994. 'Gender Differences and the Use of Conflict Strategies.' In Differences That Make a Difference, edited by L. H. Turner and R. M. Sterk, 24-34. Westport, ст: Bergin and Garvey.

Gerhart, B., and S. Rhynes. 1991. 'Determinants and Consequences of Salary Negotiations by Male and Female mBA Graduates.' Journal of Applied Psychology 76:256-62. 
Grant, M. J., and V. Sermant. 1969. 'Status and Sex of Others as Determinants of Behavior in a Mixed-Motive Game.' Journal of Personality and Social Psychology 12:151-7.

Herbst, U., H. Dotan, and S. Stōhr. 2017. 'Negotiating with Work Friends: Examining Gender Differences in Team Negotiations.' The Journal of Business and Industrial Marketing 32 (4): 558-66.

Horai, J., and J. T. Tedeschi. 1975. 'Compliance and the Use of Threats and Promises after a Power Reversal.' Behavioral Science 20:117-24.

Hottes, J. H., and A. Kahn. 1974. 'Sex Differences in a Mixed-Motive Conflict Situation.' Journal of Personality 42:260-5.

Jap, S., D. Robertson, and R. Hamilton. 2011. 'The Dark Side of Rapport: Agent Misbehavior Face-to-Face and Online.' Management Science 57 (9): 1610-22.

Kimmel, M. J., D. B. Pruitt, J. M. Magenau, E. Konar-Goldband, and P. G. D. Carnevale. 1980. 'Effects of Trust, Aspiration, and Gender on Negotiation Tactics.' Journal of Personality and Social Psychology 38 (1): 9-22.

King, W. C., and D. Hinson. 1994. 'The Influence of Sex and Equity Sensitivity on Relationship Preferences, Assessment of Opponent, and Outcomes in a Negotiation Experiment.' Journal of Management 20 (3): 605-24.

Kray, L. J., A. D. Galinsky, and L. Thompson. 2002. 'Reversing the Gender Gap in Negotiations: An Exploration of Stereotype Regeneration.' Organizational Behavior and Human Decision Processes 87 (3): 386-409.

Kray, L. J., J. A. Kennedy, and A. B. Van Zant. 2014. 'Not Competent Enough to Know the Difference? Gender Stereotypes about Women's Ease of being Misled Predict Negotiator Deception.' Organizational Behavior and Human Decision Processes 125 (2): 61-72.

Kristensen, H., and T. Garling. 1997. 'The Effects of Anchor Points and Reference Points on Negotiation Process and Outcome.' Organizational Behavior and Human Decision Processes 71 (1): 85-94.

Kulik, C. T., and M. Olekalns. 2012. 'Negotiating the Gender Divide: Lessons from the Negotiation and Organizational Behavior Literatures.' Journal of Management 38 (4): 1387-415.

Major, B., D. B. McFarlin, and D. Gagnon. 1984. 'Overworked and Underpaid: On the Nature of Gender Differences in Personal Entitlement.' Journal of Personality and Social Psychology 47:1399-412.

Mannix, E. A., C. H. Tinsley, and M. Bazerman. 1995. 'Negotiating over Time: Impediments to Integrative Solutions.' Organizational Behavior and Human Decision Processes 62 (3): 241-51.

Matheson, K. 1991. 'Social Dues in Computer-Mediated Negotiations: Gender Makes a Difference.' Computers in Human Behavior 7:13745 .

Mazei, J., J. Huffmeier, P. A. Freund, A. F. Stuhlmacher, and L. Bilke. 
2015. 'A Meta- Analysis on Gender Differences in Negotiation Outcomes and Their Moderators.' Psychological Bulletin 141 (1): 85-104.

Meyers-Levy, J. 1988. 'The Influence of Sex Roles on Judgment.' Journal of Consumer Research 14:522-30.

Min, H., M. S. LaTour, and M. A. Jones. 1995. 'Negotiation Outcomes: The Impact of the Initial Offer, Time, Gender, and Team Size.' International Journal of Purchasing and Materials Management 31 (4): 19-24.

Mintu-Wimsatt, A., and J. B. Gassenheimer. 2002. 'The Impact of Demographic Variables on Negotiators' Problem-Solving Approach: A Two Country Study.' Journal of Marketing Theory and Practice 10 (1): 23-35.

Moon, Y., T. Yao, and S. Park. 2011. 'Price Negotiation Under Uncertainty.' International Journal of Production Economics 134 (2): 413-23.

Moore, D. A., T. R. Kurtzberg, L. L. Thompson, and M. W. Morris. 1999. 'Long and Short Routes to Success in Electronically Mediated Negotiations: Group Affiliations and Good Vibrations.' Organizational Behavior and Human Decision Processes 77 (1): 22-43.

Neu, J., J. L. Grahm, and M. C. Gilly. 1988. 'The Influence of Gender on Behaviors and Outcomes in a Retail Responder-Initiator Negotiation Simulation.' Journal of Retailing 64 (4): 427-51.

O'Connor, K. M., and A. A. Adams. 1999. 'What Novices Think About Negotiation.' Negotiation Journal 15 (2): 135-47.

O'Connor, K. M., and J. A. Arnold. 2001. 'Distributive Spirals: Negotiation Impasses and the Moderating Role of Disputant Self-Efficacy.' Organizational Behavior and Human Decision Processes 84 (1): 14876.

O'Connor, K. M., J. A. Arnold, and E. R. Burris. 2005. 'Negotiators' Bargaining Histories and Their Effects on Future Negotiation Performance.' Journal of Applied Psychology 90 (2): 350-62.

Olekalns, M., P. L. Smith, and T. Walsh. 1996. 'The Process of Negotiation: Strategy and Timing as Predictors of Outcomes.' Organizational Behavior and Human Decision Processes 68 (1): 68-77.

O'Shea, P. G., and D. F. Bush. 2002. 'Negotiation for Starting Salary: Antecedents and Outcomes among Recent College Graduates.' Journal of Business and Psychology 16 (3): 365-82.

Oskamp, S., and D. Perlman. 1965. 'Factors Affecting Cooperation in a Prisoner's Dilemma Game.' Journal of Conflict Resolution 9:359-74.

Pesendorfer, E. M., and S. T. Koeszegi. 2007. 'Social Embeddedness in Electronic Negotiations.' Group Decision and Negotiation 16 (4): 399415.

Pruitt, D. G., P. J. D. Carnevale, B. Forcey, and M. Van Slyck, 1986. 'Gender Effects in Negotiation: Constituent Surveillance and Contentious Behavior.' Journal of Experimental Social Psychology 22 (3): $264-5$. 
Riley, H. C. 2001. 'When Does Gender Matter in Negotiation? The Case of Distributive Bargaining.' Doctoral Dissertation, Harvard University, Boston, MA.

Rogers, T. A., R. A. Zeckhauser, F. A. Gino, M. A. Norton, and M. A. Schweitzer. 2017. 'Artful Paltering: The Risks and Rewards of Using Truthful Statements to Mislead Others.' Journal of Personality and Social Psychology 112 (2): 456-73.

Scudder, J. N. 1988. 'The Influence of Power on Powerful Speech: A Social-Exchange Perspective.' Communication Research Reports $5: 140-5$.

Solnick, S. J. 2001. 'Gender Differences in the Ultimatum Game.' Economic Inquiry 39 (2): 189-200.

Stamato, L. 1992. 'Voice, Place, and Process: Research on Gender, Negotiation, and Conflict Resolution.' Mediation Quarterly 9:375-86.

Stevens, C. K., A. G. Bavette, and M. E. Gist. 1993. 'Gender Differences in the Acquisition of Salary Negotiation: The Role of Goals, SelfEfficacy, and Perceived Control.' Journal of Applied Psychology 78 (5): 723-35.

Stuhlmacher, A. F., and A. E. Walters. 1999. 'Gender Differences in Negotiation Outcome: A Meta-Analysis.' Personnel Psychology 52 (3): 653-77.

Tedeschi, J. T., T. Bonoma, and S. Lindskold. 1970. 'Threateners' Reactions to Prior Announcement of Behavioral Compliance or Defiance.' Behavioral Science 15:171-9.

Tubbs, S. L., E. Ottenbreit, and S. Falk. (2008). 'Gender Bias in Automotive Negotiations.' Journal of American Academy of Business 13 (2): 182-7.

Tuncel, E. A., M. A. Mislin, S. Kesebir, and R. L. Pinkley. 2016. ‘Agreement Attraction and Impasse Aversion: Reasons for Selecting a Poor Deal over No Deal at All.' Psychological Science 27 (3): 312-21.

Trotschel, R., J. Huffmeier, D. D. Loschelder, K. Schwartz, and P. M. Gollwitzer. 2011. 'Perspective Taking as a Means to Overcome Motivational Barriers in Negotiations: When Putting Oneself into the Opponent's Shoes Helps to Walk Toward Agreements.' Journal of Personality and Social Psychology 101 (4): 771-90.

Wall, J. A., and M. W. Blum. 1991. 'Negotiations.' Journal of Management 17:273-303.

Walters, A. E., A. F. Stuhlmacher, and L. L. Meyer. 1998. 'Gender and Negotiator Competitiveness: A Meta-Analysis.' Organizational Behavior and Human Decision Processes 76:1-29.

Watson, C. 1994. 'Gender Versus Power as a Predictor of Negotiation Behavior and Outcomes.' Negotiation Journal 10:117-27.

Watson, C., and L. R. Hoffman. 1996. 'Managers as Negotiators: A Test of Power Versus Gender as Predictors of Feelings, Behavior, and Outcomes.' Leadership Quarterly 7:63-85. 
Wiltermuth, S. S., and M. Neale. 2011. 'Too Much Information: The Perils of Nondiagnostic Information in Negotiations.' Journal of Applied Psychology 96 (1): 192-201.

Wolfe, C. J., and U. S. Murthy. 2005-2006. 'Negotiation Support Systems in Budget Negotiations: An Experimental Analysis.' Journal of Management Information Systems 22 (3): 351-81.

Xiu, L. A., G. Kang, and A. C. Roline. 2015. 'Who Negotiates a Higher Starting Salary? A Moderation Model on the Role of Gender, Personality and Risk Attitude.' Nankai Business Review International 6 (3): $240-55$.

This paper is published under the terms of the Attribution-

NonCommercial-NoDerivatives 4.o International (CC BY-NC-ND 4.0)

License (http://creativecommons.org/licenses/by-nc-nd/4.o/). 